\title{
Large-scale distribution patterns of carnivores in northern South Africa: implications for conservation and monitoring
}

\author{
Michelle Thorn, Matthew Green, Mark Keith, Kelly Marnewick \\ Philip W. Bateman, Elis A Z. CAMeron and Dawn M. Scott
}

\begin{abstract}
Accurate assessment of carnivore population status is frequently hindered by insufficient distribution data. For northern South Africa we address this deficit by mapping new records from landscape-scale sign surveys, questionnaire interviews, problem animal records and camera trapping. The black-backed jackal Canis mesomelas and caracal Caracal caracal remain common and widespread. Ranges of the serval Leptailurus serval and brown hyaena Hyaena brunnea were much larger than previous estimates, reducing the risk of simultaneous extirpation across all occupied locations. The proportion of range area occupied was larger for several species, notably the leopard Panthera pardus, cheetah Acinonyx jubatus and serval. We conclude that the serval continues to recover from historical threats and is expanding into new areas. A larger brown hyaena range and less fragmented pattern of occurrence probably confers greater resilience to threats than was suggested by previous data. Reduced extinction risk arising from the increased area occupied by the cheetah and leopard is tempered by probable local range contraction. Our maps provide baseline information for monitoring the distribution of these six species, which is essential in managing ecological issues that have a spatial component such as responses to changing land use. Our results also demonstrate the utility of detection/nondetection surveys in rapid assessment of carnivore populations at large spatial scales.
\end{abstract}

Keywords Black-backed jackal, brown hyaena, caracal, cheetah, distribution, leopard, serval, South Africa

Michelle ThORN (Corresponding author) and DAwn M. SCOTT University of Brighton, Biology Division, Huxley Building, Lewes Road, Moulsecoomb, Brighton, BN2 4GJ, UK. E-mail thorn_green@hotmail.com

Matthew Green, Philip W. Bateman and Elissa Z. Cameron Mammal Research Institute, Department of Zoology and Entomology, University of Pretoria, Pretoria, South Africa

Mark KeIth School of Animal, Plant and Environmental Sciences, University of Witwatersrand, Johannesburg, South Africa

Kelly Marnewick* Endangered Wildlife Trust, Carnivore Conservation Group, Johannesburg, South Africa

*Also at: Mammal Research Institute, Department of Zoology and Entomology, University of Pretoria, Pretoria, South Africa

Received 11 November 2010. Revision requested 13 December 2010.

Accepted 18 January 2010.

\section{Introduction}

ccurate knowledge of spatial and temporal distribuA tion patterns is fundamental to species management and conservation, and assessment of extinction risks (Gaston \& Fuller, 2009). For example, $\geq 47 \%$ of threatened species in groups that have been assessed for the IUCN Red List were categorized solely on the basis of range measures (Gaston \& Fuller, 2009). These measures include extent of occurrence (EOO) and area of occupancy (AOO). EOO is the geographical area bounded by the outermost known or projected contemporary species' records, and is often considered the species' range (IUCN, 2001; Hartley \& Kunin, 2003; Gaston \& Fuller, 2009). It is used in assessing the likelihood of simultaneous extinction in all areas occupied by the species, with the assumption that extinction risk is inversely related to range size (Gaston \& Fuller, 2009). AOO is a finer scale measure comprising specific locations within the EOO where species' occurrence has been recorded, generalized to an appropriate spatial resolution (IUCN, 2001; Hartley \& Kunin, 2003; Gaston \& Fuller, 2009). It reflects the rarity and fragmentation of occupied locations and thus the likely resilience of the distribution to threats from stochastic and directional processes (Hartley \& Kunin, 2003; Gaston \& Fuller, 2009). Occupancy is another measure that expresses the proportion of an area or collection of sampling sites that are occupied and is frequently used in monitoring programmes as a surrogate for abundance (MacKenzie et al., 2006).

Unfortunately, such information is often lacking for terrestrial carnivores because they are notoriously difficult and labour intensive to detect (Nowell \& Jackson, 1996; Sillero-Zubiri et al., 2004). This data deficit was highlighted by a South African Conservation Assessment and Management Plan (Friedmann \& Daly, 2004) to update the evaluation conducted nearly 20 years previously (Smithers, 1986). As a result of this process $35 \%$ of South Africa's terrestrial carnivores were categorized nationally as threatened, Near Threatened or Data Deficient (Friedmann \& Daly, 2004). This includes the brown hyaena Hyaena brunnea and serval Leptailurus serval, categorized as Near Threatened, and the cheetah Acinonyx jubatus, categorized as Vulnerable. However, insufficient data on trends and contemporary distributions hindered accurate assessment of many species (Friedmann \& Daly, 2004). 
Here we address this problem by mapping new data from large-scale surveys in northern South Africa. We compare current and historical distributions so as to extract spatial and temporal patterns that elucidate the present conservation status of the brown hyaena, serval and cheetah, and the black-backed jackal Canis mesomelas, caracal Caracal caracal and leopard Panthera pardus, categorized as Least Concern (i.e. not currently in danger of extinction) in South Africa (Friedmann \& Daly, 2004).

\section{Study area}

The study area is the North West province of South Africa and the adjoining Thabazimbi district of the Limpopo province, which border Botswana to the north. All six of the focal species occur within and outside protected areas, most of which have fences that are permeable to free-ranging animals. Historical and contemporary provincial boundaries relevant to the discussion are shown in Fig. 1.

\section{Methods}

We collected the data presented here during an intensive study of the Thabazimbi district in 2000 and a largescale study of the North West province during 2006-2008. The cheetah was the focal species for the Thabazimbi study but we also collected data on the brown hyaena and leopard. The focal species for the study in the North West province were the brown hyaena, caracal, black-backed jackal, leopard, serval and cheetah. We carried out a number
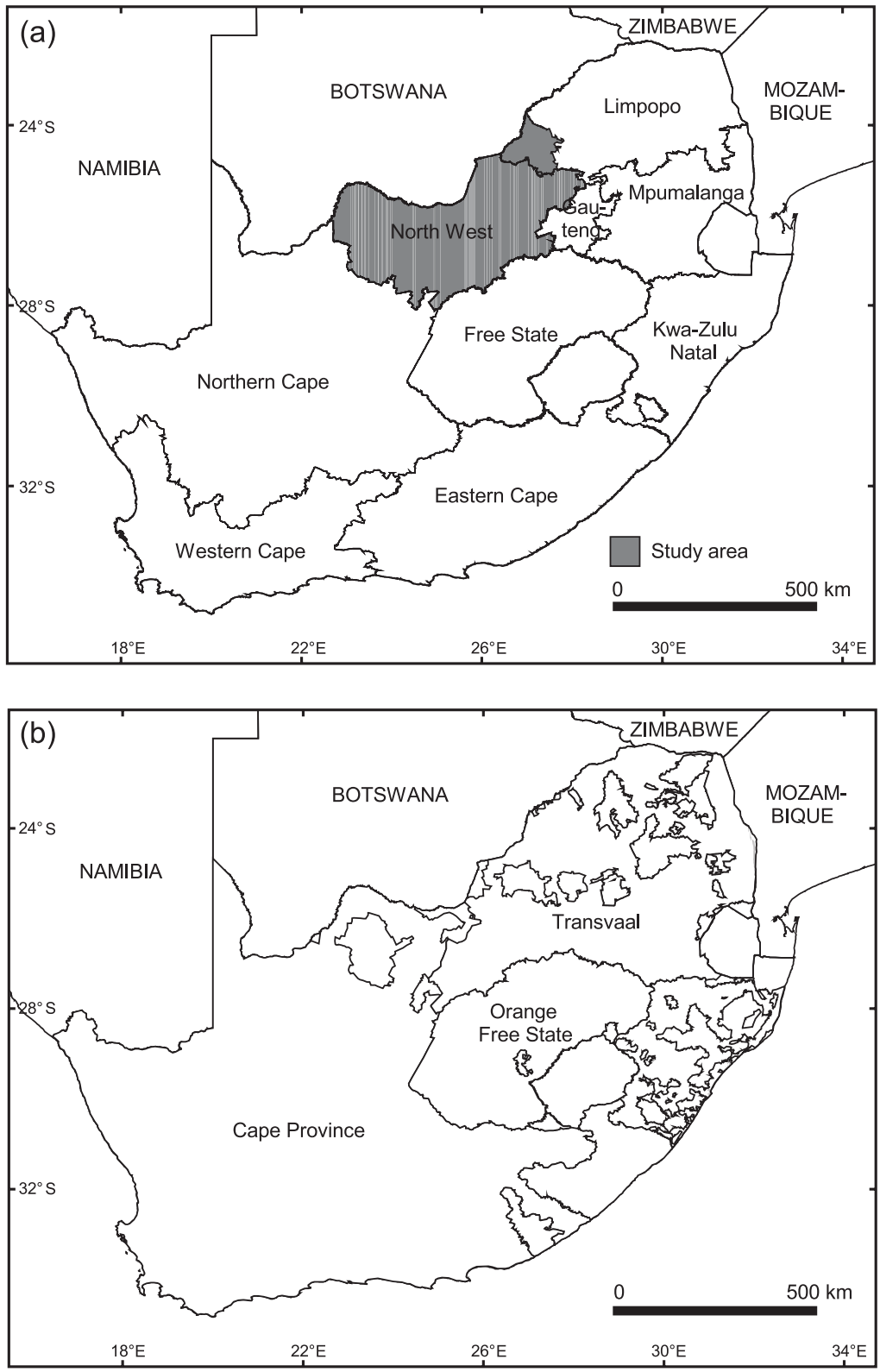

FIG. 1 (a) Current provincial boundaries and location of the study area, which comprised the North West province and Thabazimbi district, an adjoining area of Limpopo province, and (b) historical provincial boundaries in South Africa. 
of systematic, random and opportunistic surveys throughout the study area. Sampling methods included socioeconomic interviews using questionnaires, sign surveys and camera trapping. We also included records of verified complaints of problem animals lodged by landowners with the Nature Conservation Department during the same period. All observers were appropriately trained and experienced and any records with dubious reliability were excluded from analysis to minimize the likelihood of records of false presence (Karanth et al., 2009).

Questionnaire surveys involved semi-structured interviews with private landowners and managers. In the Thabazimbi district all contactable agricultural landowners were interviewed. In the North West province the primary sampling units were 25 randomly selected $415 \mathrm{~km}^{2}$ grid cells covering $16.9 \%$ of agricultural land in the province. We surveyed $\geq 2$ landowners per sampling cell but, although the majority of interviews (64\%) were conducted in the randomly selected survey cells, we also recruited additional participants at livestock auctions and farmers' meetings.

We conducted preliminary sign surveys at ranches $(n=17)$ and reserves $(n=8)$ in areas deemed representative of climatic conditions (high, medium and low annual rainfall and mean daily maximum temperature), mammal community composition (with and without apex predators, game and domestic livestock), and densities of carnivore species (within and outside protected areas). We surveyed once in the wet season and again in the dry season. The mean area of the sites surveyed was $103 \mathrm{~km}^{2}$ and we scaled effort by carrying out $\geq 1 \mathrm{~km}$ of surveys per $5 \mathrm{~km}^{2}$ of site area. We conducted all sign surveys from a vehicle travelling along unpaved roads at 10$15 \mathrm{~km} \mathrm{~h}^{-1}$ (see Thorn et al., 2010 for detailed methods). During sign surveys $\geq 2$ trained observers searched for sign (tracks and scats) on and within a 2-m strip either side of the road. Sign was identified to species based on colour, dimensions, position and presence of accompanying signs (Stuart \& Stuart, 2000) but was not aged.

Later sign surveys were conducted in the 25 randomly selected $415 \mathrm{~km}^{2}$ grid cells where we had completed questionnaire surveys in the North West province. As in the preliminary surveys we detected sign more frequently in the dry season (although the difference was not significant), when sign persists for longer; these later surveys were conducted only in the dry season. We scaled effort according to the proportion of agricultural land in the cell (following Hines et al., 2010), resulting in an effort of $11-25 \mathrm{~km}$ per cell. We used the same method as in the preliminary surveys except that the primary observer was seated in a spotter's chair fixed above the front bumper whilst a secondary observer looked for sign from within the vehicle.

We carried out a preliminary camera-trap survey at 13 of the sites where we conducted preliminary sign surveys. At that time only four passive infrared $35 \mathrm{~mm}$ cameras were available to us, restricting effort to $\geq 5$ camera days per site. Seasonal replicates were completed at nine of the 13 sites. We positioned single camera traps in locations where carnivore signs had been previously observed, to maximize detection probability (Karanth \& Nichols, 2002). They were secured to a suitable tree or bush at a height of c. $45 \mathrm{~cm}$ from the ground (Karanth \& Nichols, 2002) and baited daily with offal or animal carcasses. We set cameras to operate only at night, with time and date automatically imprinted on photographs.

Later camera-trap surveys used $35 \mathrm{~mm}$ passive infrared units set for 24 hour operation, fixed to trees, positioned to maximize detection probability, and set to imprint time and date, as in preliminary work. We carried out seven surveys in the randomly selected $415 \mathrm{~km}^{2}$ grid cells where we completed questionnaire and sign surveys in the North West province. As in initial sign surveys we chose sites that were representative of a range of climactic conditions and mammal community composition. We used 11-25 camera traps per grid cell (scaling effort in the same way as for sign surveys), with single camera traps c. $1 \mathrm{~km}$ apart along roads and trails. We baited with tinned fish and fermented eggs and left traps in place for $\geq 9$ days.

We compiled the results of the field surveys and inferred species presence from signs and sightings. We then digitized the location of each occurrence (obtained with a global positioning system) in ArcView v. 3.3 (ESRI, Redlands, USA) and plotted our new records alongside those generated during the South African Conservation Assessment and Management Plan process. The Conservation Assessment and Management Plan distribution maps (Keith, 2004) comprise a series of geographical information system shapefiles showing AOO at 1/4 degree square (QDS) level and the minimum convex polygon (MCP) representing the most likely EOO of each species between 1990 and 2000. We based our comparisons on these maps rather than on the IUCN global distribution assessments because the former incorporate more detailed local AOO knowledge for 1990-2000 and therefore are a better reflection of fine-scale national distribution during that decade (Rodríguez et al., 2000). The Conservation Assessment and Management Plan workshop that generated the maps was conducted under the auspices of the IUCN Conservation Breeding Specialist Group and the maps are consistent with IUCN criteria (IUCN, 2001). Our maps use the same QDS resolution but also show grid cells where surveys failed to detect the focal species (nondetections), and locations of breeding populations (inferred from sightings of offspring).

\section{Results}

Our sample included data from a total of 474 ranches and reserves (108 in the landscape-scale study of the North 
West province and 366 in the more intensive study of the Thabazimbi district). These properties were located in 71 of the 234 QDSs that fall wholly or partly within the study area. Complaints of problem animals added presence records of carnivores in a further eight QDSs that were not surveyed. We completed 298 questionnaire interviews, 55 sign surveys comprising a total of $1,540 \mathrm{~km}$ of effort, and 20 camera trap surveys comprising 1,571 days of trapping effort. Questionnaires were used in 62 QDSs with a mean effort of four questionnaires per QDS (range 2-39), sign surveys were used in 43 QDSs with a mean effort of $35.8 \mathrm{~km}$ per QDS (range 25-203) and camera trapping was used in 20 QDSs with a mean effort of 72 camera days per QDS (range 5-297; Fig. 2).

We estimated EOO and AOO of the six species in the study area (Table 1) from our revised distribution maps (Fig. 3). Trends were calculated as the percentage difference between our estimates and those calculated from Keith (2004). We defined EOO as extent of the study area falling within the South African MCP for the species. We calculated AOO as the summed area of all occupied QDSs $\left(1\right.$ QDS $\approx 773 \mathrm{~km}^{2}$ ) falling wholly or partly within the study area. Naive occupancy was calculated as the percentage of surveyed QDSs within the species' EOO where the species was detected.

The EOO of the black-backed jackal remained unchanged from that reported for 1999-2000. Breeding records were numerous and distributed throughout the study area. As jackal occupancy was the highest (100\%) of the focal species the negative trend in AOO probably reflects a lack of observations from our Thabazimbi survey (in which jackals were not a focal species) compared with the museum and personal observation records used in Keith (2004). If present jackal occupancy is the same in

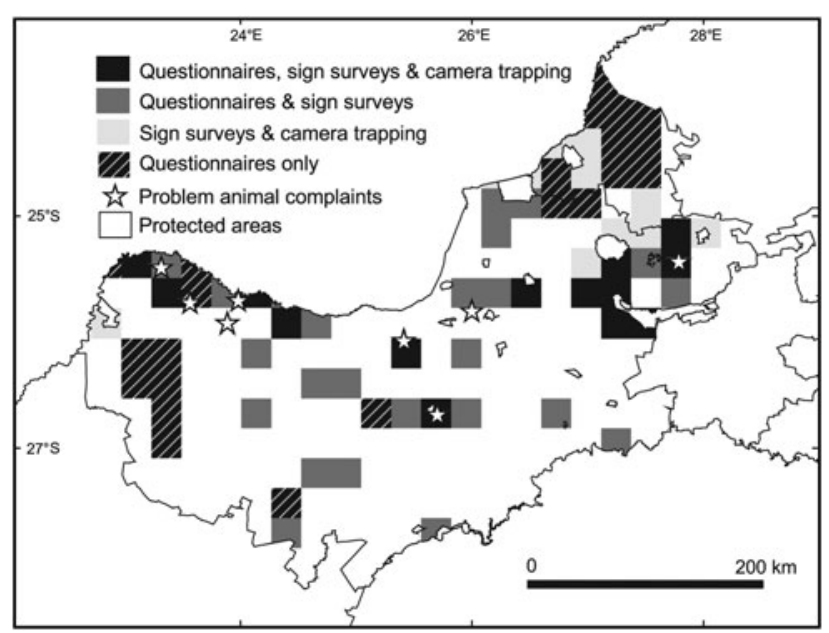

FIG. 2 Methods used to collect data in $1 / 4$ degree squares (QDS) in the North West province and Thabazimbi district (Fig. 1) between 2000 and 2008 .
Thabazimbi as in the rest of the study area, the overall trend in $\mathrm{AOO}$ would be $+8 \%$. Caracal EOO remains unchanged and, at $82 \%$, naive occupancy was high. The AOO showed a large increase and breeding reports were distributed widely throughout the study area. The serval had a naive occupancy of $81 \%$ and showed large increases in both EOO and AOO. Brown hyaenas had the highest AOO and largest increase in EOO of the focal species. Naive occupancy was 91\% but breeding records were restricted to the northern half of the study area. The increasing trend in cheetah and leopard EOO resulted from the addition of a single outlying presence record in each case, marginally increasing the MCP area. Cheetahs had 60\% naive occupancy and high AOO considering the species' restricted range. The only breeding records were along the Botswana border. Leopard AOO showed the largest increase of the focal species and naive occupancy was $73 \%$. Breeding records were restricted to the northern half of the study area, with the exception of one southern outlier.

\section{Discussion}

Prior publications providing carnivore distribution records for our study area largely relied on collections data consisting of museum records (e.g. those contained in the South African Integrated Spatial Information System), literature sources, personal observations from taxon experts, and reports from provincial authorities (Skinner, 1976; Stuart et al., 1985; Skinner \& Smithers, 1990; Gelderblom et al., 1995; Friedmann \& Daly, 2004). Such data are valuable but are often subject to quality problems such as bias towards sampling easier-to-study species or areas and omission of non-computerized records (Robertson \& Barker, 2006). Furthermore, contemporaneous field surveys were mainly confined to protected areas and as non-detections were not displayed apparently unoccupied grid cells cannot be differentiated from those that were simply data deficient. Because of this, apparent changes in distribution may arise from greater direct search effort in areas that were previously ignored or poorly sampled (Dobson \& Nowak, 2010). This is a widespread issue that confounds analysis of range trends in many biodiversity studies (Dobson \& Nowak, 2010). Our data do not suffer from such problems and thus constitute an improvement over previously available baseline records. However, the variety of sampling designs, methods and timescales involved in our fieldwork precludes universal application of sophisticated analysis. For example, the time span of the data violates the closure assumption of occupancy models (MacKenzie et al., 2006) and therefore occupancy estimates cannot be adjusted to reflect imperfect detection (false absences). Similarly, temporal and spatial heterogeneity in detection probability cannot be estimated, confounding inference of patterns in relative abundance 
TABLE 1 Estimates of minimum extent of occurrence (EOO; extent of the study area falling within the minimum convex polygon encompassing all records of the species in South Africa) and area of occurrence (AOO; the summed area of all occupied grid cells falling wholly or partly within the study area) in 2000 and 2010 for six carnivore species. Trends are expressed as the percentage difference between our estimates and those calculated from Keith (2004).

\begin{tabular}{|c|c|c|c|c|c|c|}
\hline Species & $\begin{array}{l}\text { EOO } 2000 \\
\left(\mathrm{~km}^{2}\right)\end{array}$ & $\begin{array}{l}\text { EOO } 2010 \\
\left(\mathrm{~km}^{2}\right)\end{array}$ & Trend $(\%)$ & $\begin{array}{l}\text { AOO } 2000 \\
\left(\mathrm{~km}^{2}\right)\end{array}$ & $\begin{array}{l}\text { AOO } 2010 \\
\left(\mathrm{~km}^{2}\right)\end{array}$ & Trend $(\%)$ \\
\hline Black-backed jackal Canis mesomelas & 141,331 & 141,331 & 0 & $\geq 48,684$ & $\geq 43,275$ & -11 \\
\hline Caracal Caracal caracal & 141,331 & 141,331 & 0 & $\geq 18,546$ & $\geq 35,547$ & +92 \\
\hline Serval Leptailurus serval & 43,230 & 59,366 & +37 & $\geq 7,728$ & $\geq 16,228$ & +110 \\
\hline Brown hyaena Hyaena brunnea & 90,598 & 131,523 & +45 & $\geq 37,093$ & $\geq 48,684$ & +31 \\
\hline Cheetah Acinonyx jubatus & 66,393 & 70,451 & +6 & $\geq 8,500$ & $\geq 23,956$ & +182 \\
\hline Leopard Panthera pardus & 128,213 & 137,474 & +7 & $\geq 12,364$ & $\geq 36,320$ & +194 \\
\hline
\end{tabular}

(Karanth \& Nichols, 2002). Although these analyses could be applied to a subset of the data, the results could not be generalized to reveal landscape-scale or long-term trends, which is our aim here.

\section{Historical and present extent of occurrence}

South African wildlife populations were depleted by colonial settlers and then almost extirpated by crop and livestock farmers in the early part of the 2oth century (Pringle \& Pringle, 1979; Bothma et al., 2009). Black-backed jackals began to appear in the highveld (east central South Africa) from 1953 (Walton \& Joly, 2003), suggesting range expansion or recolonization. Pringle \& Pringle (1979) mentioned increasing numbers of caracals in eastern areas from c. 1970. Keith (2004) recorded that black-backed jackals and caracals were distributed throughout the study area by 2000. Our results provide no evidence of recent changes in EOO and thus we conclude that these species remain widespread.

In the latter half of the 2oth century the serval was considered extinct in many areas of its historical range (Stuart, 1985; Smithers, 1986; Skinner \& Smithers, 1990; Hermann et al., 2008) because of competitive exclusion by expanding caracal populations (Stuart, 1985). Brown hyaenas were widespread in the Transvaal (Smithers, 1986; Skinner \& Smithers, 1990) but thought to inhabit only $25 \%$ of their historical range in the Cape province (Stuart et al., 1985). We found a marked increase in EOO of both servals and brown hyaenas, indicating possible range expansion. This finding is corroborated by new serval occurrences in parts of the Free State and in southern areas of the North West province (Hermann et al., 2008). The positive trend in brown hyaena EOO stemmed mainly from numerous detections in areas previously excluded from the species' range as obviously unsuitable habitat (e.g. extensive crop land). A breeding record and inactive den in these areas indicate that at least some individuals are resident, supporting inclusion of these areas in our map of the species' EOO. The EOO of the serval and brown hyaena is considerably larger than previous estimates, substantially reducing the likelihood of comprehensive local extinction.

The historical distribution of cheetahs in South Africa is uncertain (Marnewick et al., 2007) but hunting and museum records indicate they certainly occurred as far south as the Western Cape province (Sclater, 1990). The 2004 assessment recorded cheetah presence only in a narrow strip along the northern border with Botswana (Friedmann \& Daly, 2004; Keith, 2004). Current EOO in our study area is similar but distorted by the presence of one or two individuals in Pilanesberg National Park and an outlying presence record prior to 2000. Frequent nondetections and a lack of recent records of presence suggest that the south-eastern extremity of the MCP should be excluded from the species' range in the near future unless the population in Pilanesberg recovers substantially.

By 2000 leopards remained widespread except in the south-east of the study area (Keith, 2004). We recorded a highly fragmented AOO in the south, which is often associated with the outer edge of a species range (Brown, 1984). This pattern increases the likelihood of range contraction if contiguous threats intensify. Frequent nondetection in the south suggests that this may already have occurred. However, a comprehensive survey of the southeastern area is needed to demarcate definitively the range boundary and the EOO therefore remains unchanged pending confirmation of our findings.

\section{Area of occupancy and naive occupancy}

The home ranges of the black-backed jackal and serval are much smaller than a QDS. For example, mean home range for jackals in an ecologically similar study area in Botswana was $15.9 \mathrm{~km}^{2}$ (Kaunda, 2001). If occupancy within QDSs is patchy, generalizing to the scale of QDSs may overestimate the area actually occupied. Absolute AOO values for these species should therefore be interpreted with caution. AOO for wide ranging species such as the brown hyaena, caracal, leopard and cheetah probably approximate better the land area they occupy, although positive bias is still possible. 

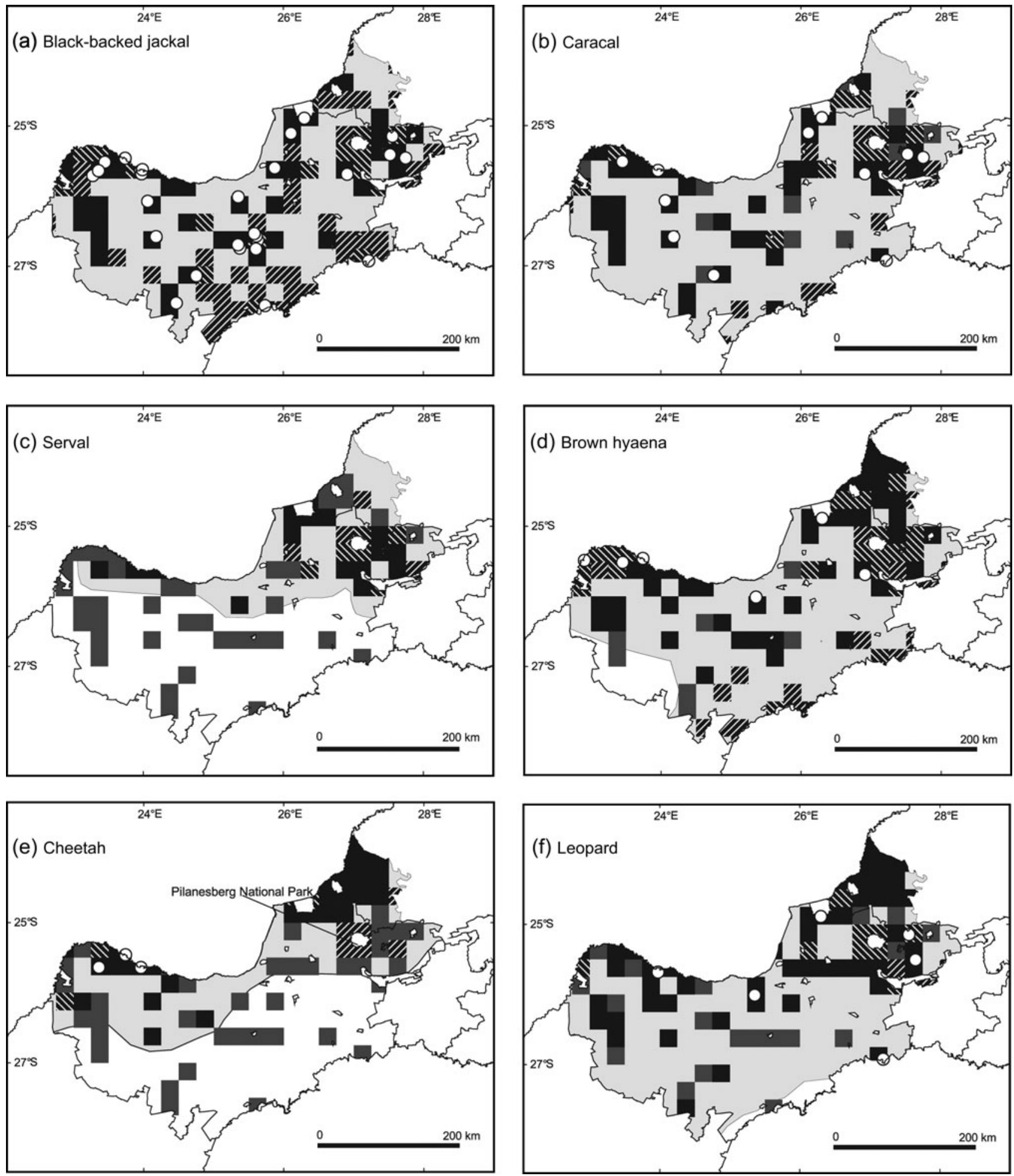

FIG. 3 Distribution maps showing the $1 / 4$ degree squares (QDS) in the North West province and Thabazimbi district (Fig. 1) believed occupied by each of the six carnivore species during 1990-2000 (Keith, 2004) and the QDS where we measured occupancy during 20002008: (a) black-backed jackal Canis mesomelas, (b) caracal Caracal caracal, (c) serval Leptailurus serval, (d) brown hyaena Hyaena brunnea, (e) cheetah Acinonyx jubatus, (f) leopard Panthera pardus. Extent of occurrence (EOO) is the minimum convex polygon containing all South African records of the species, intersected with the study area. Z QDS believed occupied during 1990-2000 (Keith, 2004) but not resampled in our surveys. Q QDS where we detected the species during 2000-2008 but Keith (2004) did not. N QDS where both our study and Keith (2004) reported the species. Q QDS where we did not detect the species. $\square$ Revised EOO taking account of new data from this study. $\square$ Areas falling outside of the EOO polygon or excluded in Keith (2004) as unsuitable habitat. $\oslash$ Protected areas. $\bigcirc$ Breeding records from this study. 
However, actual occupancy is frequently greater than naive occupancy because species that are present are not always detected. We did not sample comprehensively and thus it is also likely that at least some QDSs that were not sampled are occupied, especially those reportedly occupied in Keith (2004) and not re-sampled in our surveys. In view of this our AOO estimates are probably conservative, particularly for widespread species with large home ranges.

The black-backed jackal assessment in Friedmann \& Daly (2004) considered the species abundant and common. We found $100 \%$ occupancy and our numerous, extensive breeding records also suggest high fecundity. In view of this and because $\mathrm{AOO}$ at fine spatial scales is often correlated with population size (Gaston \& Fuller, 2009), we conclude that the species remains abundant. Friedmann \& Daly (2004) also considered the caracal common, and high occupancy, increasing AOO and extensive breeding records indicate that this is probably still the case. Both species seem to have recovered well from historical threats and appear resilient to contemporary pressures.

Our AOO data for leopards shows the highest increase of the focal species and indicates that they currently inhabit large areas of the northern half, and especially the northeast, of the study area. The distribution of breeding records and fragmented AOO pattern observed in the south implies residence mainly in the north. Cheetah AOO showed a marked increase and occupancy was relatively high given the restricted range of the species. Whether increased AOO reflects higher occupancy or search effort, current patterns for both the leopard and cheetah should afford a greater degree of resilience to threats than would have been predicted from previous records (Gaston \& Fuller, 2009). However, in both cases restricted and probably contracting ranges argue for precautionary monitoring of local status.

High occupancy for the serval, a large increase in AOO and apparent range expansion indicates continued recovery from historical threats. According to species' accounts, the serval is rarely found in arid areas and their distribution is restricted to high rainfall areas with riparian habitat (Nowell \& Jackson, 1996). However, serval records from sign and questionnaire surveys were evenly divided between sites with annual rainfall of $\leq 400$ and $\geq 400 \mathrm{~mm}$, indicating that the species is more tolerant of arid conditions than previously thought. Hermann et al. (2008) contended that this is mainly due to the creation of man-made water bodies, which provide suitable habitat for serval prey.

The brown hyaena was formerly considered rare in the Transvaal (Smithers, 1986; Skinner \& Smithers, 1990) but our high estimates of AOO and occupancy together with an increasing $\mathrm{AOO}$ indicate that this is no longer the case. Evidence of brown hyaena breeding was restricted to the northern half of the study area but the southern AOO pattern does not show the fragmentation usually associated with the edge of a species' range. Future studies may therefore reveal breeding clans further south. High occupancy in extensive crop land demonstrates a greater than expected tolerance of degraded habitat, and current AOO, together with a larger estimate of EOO, gives cause for cautious optimism about the local status of this species.

\section{Implications for future studies}

Ideally, researchers and conservation practitioners should measure landscape-scale patterns in distribution, occupancy and relative abundance by conducting large-scale surveys using standardized methods that account for issues of spatial sampling and detectability. In practice, cost and logistical difficulties frequently restrict the extent and intensity of carnivore surveys (Thorn et al., 2010), which is one of the main reasons landscape-scale distribution data are so scarce. Our records were gathered relatively quickly by a small team operating over a large area and demonstrate the value of synthesizing results from multiple smaller-scale surveys (Karanth et al., 2009; Pettorelli et al., 2010). We constructed a finescale, contemporary snapshot of large-scale patterns that will facilitate monitoring of distributions (Dobson \& Nowak, 2010). This is fundamental to managing ecological challenges that have a spatial component, such as protected area network design and measuring the impact of changes in environmental variables such as climate or land use (Gelderblom et al., 1995; Rodríguez et al., 2000; Hartley \& Kunin, 2003; Karanth et al., 2009; Pettorelli et al., 2010). Our results illustrate the utility of relatively simple detection/non-detection surveys in rapid assessment of carnivore distribution at large spatial scales. Such surveys can also be used to evaluate patterns of species richness and endemism (O'Brien, 2008) and to extrapolate distribution patterns to areas that have not been surveyed (Karanth et al., 2009). Such applications are of increasing importance in view of global population declines and accelerating anthropogenic impacts on biodiversity (Karanth et al., 2009; Pettorelli et al., 2010).

\section{Acknowledgements}

We are indebted to the private landowners, the tribal authorities in Heuningvlei, Tshidilamololo and Ganyesa, and the North West Parks and Tourism Board, who allowed us to survey their land. We thank G. Gaboinewe and G.S. Molale, who helped administer questionnaires in Heuningvlei, R. Yarnell of Project Phiri, N. Ball for collecting data in Madikwe Game Reserve, V. Jacobs of the North West Department of Agriculture, Conservation and Environment for contributing problem animal records, and S. Uzzell for computer equipment. We are grateful to the University of Brighton, UK, the Leverhulme Trust UK Chester Zoo, UK, and the Earthwatch Institute for funding. 


\section{References}

Bothma, J.D.P., Suich, H. \& Spenceley, A. (2009) Extensive wildlife production on private land in South Africa. In Evolution and Innovation in Wildlife Conservation: Parks and Game Ranches to Transfrontier Conservation Areas (eds H. Suich, B. Child \& A. Spenceley), pp. 147-162. Earthscan, London, UK.

Brown, J.H. (1984) On the relationship between abundance and distribution of species. American Naturalist, 124, 255-279.

Dobson, A. \& NowaK, K. (2010) Does this photo make my range look big? Animal Conservation, 13, 347-349.

Friedmann, Y. \& Daly, D. (eds) (2004) Red Data Book of the Mammals of South Africa: A Conservation Assessment. Conservation Breeding Specialist Group Southern Africa (Species Survival Commission/IUCN) \& The Endangered Wildlife Trust, Johannesburg, South Africa.

Gaston, K.J. \& Fuller, R.A. (2009) The sizes of species' geographic ranges. Journal of Applied Ecology, 46, 1-9.

Gelderblom, C.M., Bronner, G.N., Lombard, A.T. \& Taylor, P.J. (1995) Patterns of distribution and current protection status of the Carnivora, Chiroptera and Insectivora in South Africa. South African Journal of Zoology, 30, 103-114.

Hartley, S. \& Kunin, W.E. (2003) Scale dependency of rarity, extinction risk, and conservation priority. Conservation Biology, $17,1559-1570$.

Hermann, E., Kalmer, J.F. \& Avenant, N.L. (2008) New records of servals (Leptailurus serval) in central South Africa. South African Journal of Wildlife Research, 38, 185-188.

Hines, J.E., Nichols, J.D., Royle, J.A., MacKenzie, D.I., Gopalaswamy, A.M., Samba Kumar, N. \& Karanth, K.U. (2010) Tigers on trails: occupancy modeling for cluster sampling. Ecological Applications, 20, 1456-1466.

IUCN (2001) IUCN Red List Categories and Criteria: Version 3.1. IUCN Species Survival Commission, Gland, Switzerland.

Karanth, K.U. \& Nichols, J.D. (eds) (2002) Monitoring Tigers and Their Prey: A Manual for Researchers, Managers and Conservationists in Tropical Asia. Centre for Wildlife Studies, Bangalore, India.

Karanth, K.K., Nichols, J.D., Hines, J.E., Karanth, K.U. \& Christensen, N.L. (2009) Patterns and determinants of mammal species occurrence in India. Journal of Applied Ecology, 46, 1189-1200.

KAUNDA, S.K.K. (2001) Spatial utilization by black-backed jackals in southeastern Botswana. African Zoology, 36, 143-152.

KeIth, M. (ed.) (2004) Geographic Information System (GIS) Data of South African Mammals. Department of Zoology and Entomology, University of Pretoria, Pretoria, South Africa.

Mackenzie, D.I., Nichols, J.D., Royle, J.A., Pollock, K., Bailey, L. \& Hines, J.E. (2006) Occupancy Estimation and Modelling: Inferring Patterns and Dynamics of Species Occurrence. Elsevier Publishing, London, UK.

Marnewick, K., Beckhelling, A., Cilliers, D., Lane, E., Mills, G., Herring, K. et al. (2007) The status of the cheetah in South Africa. Cat News, Special issue 3, 22-31.

Nowell, K. \& JACKSon, P. (eds) (1996) Wild Cats. Status Survey and Conservation Action Plan. IUCN/Species Survival Commission Cat Specialist Group. IUCN, Gland, Switzerland.

O'BRIEN, T.G. (2008) On the use of automated cameras to estimate species richness for large- and medium-sized rainforest mammals. Animal Conservation, 11, 179-181.

Pettorell, N., Lobora, A.L., Msuha, M.J., Foley, C. \& Durant, S.M. (2010) Carnivore biodiversity in Tanzania: revealing the distribution patterns of secretive mammals using camera traps. Animal Conservation, 13, 131-139.
Pringle, J.A. \& Pringle, V.L. (1979) Observations on the lynx Felis caracal in the Bedford district. South African Journal of Zoology, $14,1-4$.

Robertson, M.P. \& BArker, N.P. (2006) A technique for evaluating species richness maps generated from collections data. South African Journal of Science, 102, 77-84.

Rodríguez, J.P., Ashenfelter, G., Rojas-Suárez, F., Fernández, J.J.G., SuÁrez, L. \& Dobson, A.P. (2000) Local data are vital to worldwide conservation. Nature, 403, 241.

Sclater, P.L. (1990) 1877 Felis lanea the woolly cheetah. Proceedings of the Royal Society of London, 532-533. In The Mammals of the Southern African Sub-Region (eds J.D. Skinner \& R.H.N. Smithers), pp. 392. University of Pretoria, Pretoria, South Africa.

Sillero-Zubiri, C., Hoffmann, M. \& Macdonald, D.W. (eds) (2004) Canids: Foxes, Wolves, Jackals and Dogs. Status Survey and Conservation Action Plan. IUCN/Species Survival Commission Canid Specialist Group. IUCN, Gland, Switzerland.

SkinNeR, J.D. (1976) Ecology of the brown hyaena Hyaena brunnea in the Transvaal with a distribution map for southern Africa. South African Journal of Science, 72, 262-269.

Skinner, J.D. \& S Mithers, R.H.N. (1990) The Mammals of the Southern African Sub-Region. University of Pretoria, Pretoria, South Africa.

Smithers, R.H.N. (1986) South African Red Data Book: Terrestrial Mammals. South African National Scientific Programmes Report No. 125. Council for Scientific and Industrial Research, Pretoria, South Africa.

STUART, C.T. (1985) The status of two endangered carnivores occurring in the Cape Province, South Africa, Felis serval and Lutra maculicollis. Biological Conservation, 35, 375-382.

Stuart, C.T., Macdonald, I.A.W. \& Mills, M.G.L. (1985) History, current status and conservation of large mammalian predators in the Cape Province, Republic of South Africa. Biological Conservation, 31, 7-19.

Stuart, C. \& Stuart, T. (2000) A Field Guide to the Tracks and Signs of Southern and East African Wildlife. Struik, Cape Town, South Africa.

Thorn, M., Green, M., Bateman, P., Cameron, E.Z., Yarnell, R. \& S CоTT, D. (2010) Comparative performance of sign surveys, spotlighting, and audio playbacks in a landscape-scale carnivore survey. South African Journal of Wildlife Research, 40, 77-86.

Walton, L.R. \& Joly, D.O. (2003) Canis mesomelas. Mammalian Species, 715, 1-9.

\section{Biographical sketches}

Michelle Thorn and Matthew Green's interests include patterns and determinants of mammal distribution, the development of practical field protocols for conservation monitoring and the management of human-animal conflicts. MARK KEITH focuses on the ecology and conservation of small- to medium-sized mammals, specifically to improve our understanding of lesser-known species. Kelly Marnewick is the manager of the Endangered Wildlife Trust's Carnivore Conservation Programme. She is particularly interested in cheetahs outside protected areas and resolution of human-wildlife conflict. BILL B ATEMAN's research interests include African carnivores and urban and non-native carnivores in Australia. Elissa Cameron works on the behaviour and ecology of large mammals, particularly ungulates. Her focus is on sexual conflict and the resulting impacts on behaviour, ecology and social structure. DAwn Scot T's research specialisms are in mammalian conservation biology and landscape ecology and she is the principal investigator of the Brown Hyaena Research Project in South Africa. 